\title{
Pyruvate kinase activation and lipoperoxidation after selective hepatic ischemia in wistar rats $^{1}$
}

\author{
Ativação da piruvato quinase e lipoperoxidação após \\ isquemia hepática seletiva em ratos wistar
}

\author{
Ilka de Faátima Santana Ferreira Boin ${ }^{2}$, Orlando de Castro e Silva ${ }^{3}$, Maria Eliza Jordani de Souza ${ }^{4}$, Antonio Cardoso \\ Santos $^{5}$, Luiz Sergio Leonardi ${ }^{6}$
}

1. Study Estudy performed in the Laboratory of Biochemistry of Liver Transplantation Unit of the Departament of Surgery and Anatomy of Ribeiraão Preto Faculty of Medicine-University of São Paulo (FMRP-USP), Brazil.

2. Assistant Professor - Digestive Surgery Department - Experimental Liver Transplantation Laboratory - Experimental Surgery Nucleous - Faculty of Medical Sciences - State University of Campinas - (UNICAMP), São Paulo, Brazil.

3. Full professor and Head of Unit of Liver Transplantation of Division of Gastroenterology of the Department of Surgery and Anatomy, of Ribeirao Preto- Faculty of Medicine-University of Sao Paulo(FMRP-USP), Brazil.

4. Biochemist of Biochemistry of Laboratory ofPhamaceutical Biochemistry of Unit of Liver Transplantation of the Departament of Surgery and Anatomy, (of Ribeirao Preto Faculty of Medicine-University of Sao PauloFMRP-USP), Brazil

5. Associate Professor of the Toxicology DivisionDiscipline - Faculty of Pharmaceutical Sciences of Ribeirão Preto - University of São Paulo - Brazil-USP (FCFRP-USP), Brazil..

6. Full Professor-Digestive Surgery Department - Faculty of Medical Sciences (UNICAMP), Brazil. -

\begin{abstract}
Purpose: Hepatic ischemia and reperfusion can cause several problems in hepatic surgery. The aim of this study was to determine pyruvate kinase activation and lipid peroxidation after hepatic ischemia. Methods: Twenty-four Wistar rats were submitted to 90 minutes of selective liver ischemia and 15 minutes of reperfusion. Twelve animals were submitted to selective liver ischemia and reperfusion (Group A) and the other 12 were submitted to sham operation (Group B). After 15 minutes of reperfusion, the following parameters were measured: mean arterial pressure (MAP), alanine aminotransferase (ALT), glycemia (GLY), hepatic glycogen (GH), pyruvate kinase (PK) activation, hepatic glutathione (GSH) and malondialdehyde (MDA). Analysis of the results were made by the Student t-test and has been considered significant difference for $\mathrm{p}<0.05$. Results: A and B were differents for all parameters analized. Conclusion: The animals of group A showed reperfusion syndrome with a fall in MAP, activation of glycid metabolism through the glycolitic pathway and presence of lipid peroxidation compared to group B.
\end{abstract}

Key words: Pyruvate kinase. Lipid Peroxidation. Liver Ischemia.

\section{RESUMO}

Objetivo: A isquemia e reperfusão hepática podem causar graves repercussões hepatocelulares em cirurgias hepáticas. $\mathrm{O}$ objetivo deste estudo foi determinar o comportamento da piruvato EM PORTUGUÊS quinase e a lipoperoxidação após isquemia hepática. Métodos: Foram utilizados vinte e quatro ratos Wistar machos divididos em dois grupos. Doze animais foram submetidos a 90 minutos de isquemia hepática seletiva e reperfusão hepática de por 15 minutos (pressão arterial média (PAM), alanina aminotransferase (ALT), glicemia (GLI), gicogênio hepático (GH), ativação da piruvato quinase (PQ), glutationa hepática (GSH) e malondialdeído (MDA). Os resultados foram analisados utilizando o teste t de Student sendo as diferenças consideradas significativas para $p<0,05$. Resultados: Verificou-se diferença significativa entre os grupos em todos os parâmetros analisados. Conclusão: Verificou-se que os animais do grupo A mostraram síndrome de reperfusão com queda da PAM, ativação do metabolismo da glicose através da via glicolítica e presença de lipoperoxidação quando comparada com o grupo B.

Descritores: Piruvato quinase. Peroxidação Lipídica. Fígado. Isquemia. Reperfusão.

\section{Introduction}

It has become increasingly apparent that the events resulting in cellular injury during periods of tissue hypoxia or anoxia occur primarily during reoxygenation ${ }^{1,2}$. The lack of oxygen during ischemia reduces oxidative phosphorylation, rapidly reducing existing cellular ATP stores. Paradoxically, reperfusion of the organ suddenly exposing the mitochondria to oxygen leads to the production of oxygen-derived free radicals, which are highly reactive molecules. It has been estimated that, under physiological conditions, 2 to $5 \%$ of the total oxygen consumed by mitochondria results in the formation of superoxide free radicals $\left(\mathrm{O}^{\circ}\right)$ resulting in to a single electron reduction of 
oxygen in the electron transport chain. However, mitochondria have an efficient antioxidant system represented by the enzymes superoxide dismutase, glutathione peroxidase, glutathione reductase, NAD(P) trans-hydrogenase, and other compounds such as glutathione (GSH), malondialdehyde (MDA), NADPH, and vitamins $\mathrm{C}$ and $\mathrm{E}$, which are fully balanced under normal conditions. However, when free radicals are generated in excess, this system collapses and a state of oxidative stress is created which leads to dysfunction and permeabilization of mitochondria as a consequence of a series of changes in the components of the mitochondrial membrane such as lipid peroxidation and protein-thiol oxidation ${ }^{1,2}$. The factors that most influence the release of these reactive species are ischemia and subsequent reperfusion of the organ during hepatic surgical procedures. The changes observed after the period of ischemia/reperfusion are reflected by disorders in microcirculation, hypotension, elevation of serum aminotransferase and lactate dehydrogenase levels, mitochondrial dysfunction, increased lipoperoxidation, variations of glutathione, changes in cell structure, and cell death ${ }^{3,4,5,6}$. These alterations are the consequence of a complex interaction between ATP consumption, intracellular ion influx, microvascular disorders, release of inflammatory mediators and oxygen-derived free radicals, as well as activation of neutrophils, platelets, Kupffer cells and endothelial cells, which induces the release of proteases and phospholipases that potentially damage the cellular

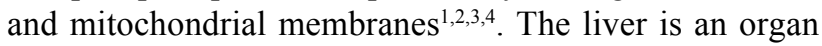
that plays a central role in energy metabolism, especially glucose metabolism. Normal glucose consumption by hepatocytes is accompanied by phosphorylation to glucose 6-phosphate which may follow various metabolic routes depending on supply and demand. Glucose 6-phosphate preferentially maintains sufficient blood glucose levels to supply energy to the brain and other tissues, and the glucose that is not immediately utilized is stored as hepatic glycogen. During the process of ischemia/reperfusion, changes occur in these metabolic pathways and the modified energy metabolism may worsen the pre-existing hepatic dysfunction ${ }^{3,4,5,6,7,8}$. Previous studies from our laboratory have shown a change in the metabolic pattern of the liver from the glycogenetic to glycolytic way due to a functional ischemic process during extrahepatic biliary obstruction (A). Pyruvate kinase (PK) is a key enzyme that coordinates gluconeogenesis and glycolysis since its inhibition is essential to permit the activation of the gluconeogenesis pathway. Thus, the objective of the present study was to investigate the changes caused by hepatic ischemia and reperfusion in energy metabolism (PK activity, blood glucose concentration and hepatic glycogen content) and the occurrence of lipoperoxidation (GSH and MDA content) and their correlation with changes in hepatic function, as well as the applicability of these parameters to the ischemia and reperfusion syndrome.

\section{Methods}

The study was conducted in the Laboratory of Surgical Hepatology and Experimental Surgery, Faculty of Medicine of Ribeirão Preto and the Laboratory of Liver Unit
Transplantation - Unicamp. Twenty-four male Wistar rats weighing 270 to $320 \mathrm{~g}$ were anesthetized with sodium pentobarbital $(50 \mathrm{mg} / \mathrm{kg})$ through the caudal vein after a 12 hour fast but with water "ad libitum". The abdomen was shaved and the right carotid artery was dissected and cannulated with a P50 catheter for blood collection for the measurement of electrolytes and glycemia and for the determination of mean arterial pressure with a Siemens instrument. Median laparotomy was performed and the lateral and middle left liver lobes were exposed. Selective clamping of the portal triad of these lobes was performed for 90 minutes in 12 rats (group A). While 12 other rats were submitted to a sham operation (group B). Fifteen minutes after releasing the clamp occluding the left portal triad (reperfusion), blood was collected by puncturing the inferior vena cava for measurement of alanine aminotransferase (ALT). Mean arterial pressure was measured and the lateral and left median lobes were collected for biochemical tissue determinations.

- Biochemical analyses - Serum ALT was determined by a kinetic method optimized by the Labtest Sistemas Diagnósticos Ltda. Laboratory, and is reported as U/L. Glycemia was determined by a kinetic method using glucose oxidase and peroxidase and is reported as $\mathrm{mg} \%$.

- Hepatic tissue analyses - For the mitochondrial preparation, the liver lobes were immediately placed in a vessel containing ice-cold physiological saline ( 0 to $4 \mathrm{C}$ ), cut into small fragments and transferred to another vessel containing ice-cold physiological saline for the removal of clots and blood from the fragments. The fragments were then placed in homogenization medium containing $0.25 \mathrm{M}$ sucrose, $1 \mathrm{mM}$ EDTA and $1 \mathrm{mg} / \mathrm{ml}$ albumin, $\mathrm{pH}$ 7.4. The material was homogenized in a Potter-Elvehjem blender for three cycles of about three seconds each, with a 1 minute interval between cycles. The mitochondrial fraction was isolated from the homogenate by the Pedersen differential centrifugation technique. The homogenate obtained was centrifuged with a refrigerated Hitachi Himac $\mathrm{Cr} 21$ centrifuge (Japan) at $1080 \mathrm{~g}$ for 5 minutes and the resulting supernatant was centrifuged at $7690 \mathrm{~g}$ for 10 minutes. The supernatant of this centrifugation was stored in $0.3 \%$ glycerol for the determination of PK activity and the sediment was resuspended to the original volume in isolation medium (0.25 M sucrose and $1 \mathrm{mM}$ EDTA, $\mathrm{pH}$ 7.4) using an "ice finger" and again centrifuged at $9000 \mathrm{~g}$ for 10 minutes. The final suspension (mitochondrial fraction) was then frozen at $-70^{\circ} \mathrm{C}$ for the determination of lipoperoxidation. The tubes were placed in crushed ice throughout the procedures, with the temperature kept at 0 to $4^{\circ} \mathrm{C}$.

- Determinationof hepatic glycogen - The glycogen content was determined in frozen specimens of livers isolated from rats. ${ }^{9}$

- Evaluation of mitochondrial lipoperoxidation Mitochondrial fraction samples frozen at -70 C were sent to the Analytical Laboratory of the Discipline of Toxicology, Faculty of Pharmaceutical Sciences of Ribeirão Preto, University of São Paulo, for the determination of indicators 
of mitochondiral lipoperoxidation (hepatic mitochondrial GSH and MDA).

- Determination of Hepatic MDA content: The mitochondiral fraction was diluted with $1.15 \% \mathrm{KCl}$ in order to obtain a protein concentration of $10 \mathrm{mg} / \mathrm{ml}$ suspension and $0.2 \mathrm{ml} 8.1 \%$ sodium dodecyl sulfate, $1.5 \mathrm{ml} 20 \%$ acetic acid, $\mathrm{pH} 3.5$, and $0.1 \mathrm{ml}$ of a $0.8 \%$ thiobarbituric acid solution were added to this suspension, plus water to a final volume of $4.0 \mathrm{ml}$. The mixture was then heated at $95 \mathrm{C}$ for 60 minutes, the vessel containing the solution was cooled with running water and $1 \mathrm{ml}$ distilled water plus $5 \mathrm{ml} \mathrm{n}$-butanol were added. The test tube containing the solution thus obtained was placed in a Phoenix shaker for 20 minutes and then centrifuged at $3500 \mathrm{~g}$ for 10 minutes. The absorbance of the organic phase was determined at $532 \mathrm{~nm}$. MDA concentration was calculated from a calibration curve obtained to the procedure described above. The unit of MDA concentration is reported as $\mathrm{nmol} / \mathrm{mg}$ protein.

- Determination of hepatic GSH content - A $1.9 \mathrm{ml}$ aliquot of $1.15 \% \mathrm{KCl}$ was added to $0.1 \mathrm{ml}$ of the mitochondrial fraction so as to obtain $2 \mathrm{mg}$ protein $/ \mathrm{ml}$ after which $0.2 \mathrm{ml}$ trichloroacetic acid $(1 \mathrm{~g} / \mathrm{ml})$ was added and then the mixture was shaken and centrifuged at $35000 \mathrm{~g}$ for 10 minutes. Two $\mathrm{ml}$ of the buffer solution $(400 \mathrm{mM}$ Tris- $\mathrm{HCl}$ and $20 \mathrm{mM}$ EDTA, pH 8.9) plus $0.1 \mathrm{ml} 10 \mathrm{mM}$ dinitrobenzene in methanol were added and the mixture was shaken. Absorbance was determined at $412 \mathrm{~nm}$ after 5 minutes. The unit of the GSH concentration obtained is reported as $\mathrm{nmol} / \mathrm{mg}$ protein.

- Evaluation of pyruvate kinase activation - PK activity was determined by the spectrophotometric method $^{10}$. The supernatant of the second centrifugation (1 $\mathrm{mg}$ protein $/ \mathrm{ml}$ ) was added to a reaction medium containing 0.1 M Tris-HCl, pH 7.4, 4 mM KCl, $0.15 \mathrm{mM} \mathrm{MgCl}_{2}, 5 \mu \mathrm{M}$ $\mathrm{NADH}$, lactate dehydrogenase, $2 \mathrm{mM}$ ADP, and $0.05 \mathrm{mM}$ phosphoenolpyruvate at a final volume of $1.0 \mathrm{ml}$ and the basal activity of the enzyme was measured. Fructose 1,6diphosphate (20 mM FDP) was then added and the enzyme activation was determined. Under these conditions, 1 unit of the enzyme catalyzed the formation of $1 \mathrm{ml}$ pyruvate per minute. $^{10}$

- Statitical analysis - Data were analyzed statistically by the Student t-test for independent samples, with the level of significance set at $\mathrm{p}<0.05$.

\section{Results}

Mean arterial pressure was $85 \mathrm{mmHg}$ for group A (ischemia and reperfusion); a lower value than $103 \mathrm{mmHg}$ was obtained for group B (sham operation). Mean ALT concentration was $1013 \mathrm{IU} / 1$ for group A and $37 \mathrm{U} / 1$ for group B. Mean glycemia was significantly higher in the ischemic group being $262 \mathrm{mg} \%$ while in the sham-operated group it was $120 \mathrm{mg} \%$ (Figure 1). Piruvate kinase activity was significantly higher in group A, $1.82 \times 10^{-2} \mathrm{nmol} / \mathrm{mg}$ protein, than in group B with $0.66 \times 10^{-2} \mathrm{nmol} / \mathrm{mg}$ protein (Figure 3 ). The mean hepatic glycogen levels were lower in group A than in group B, as shown in Figure 4.

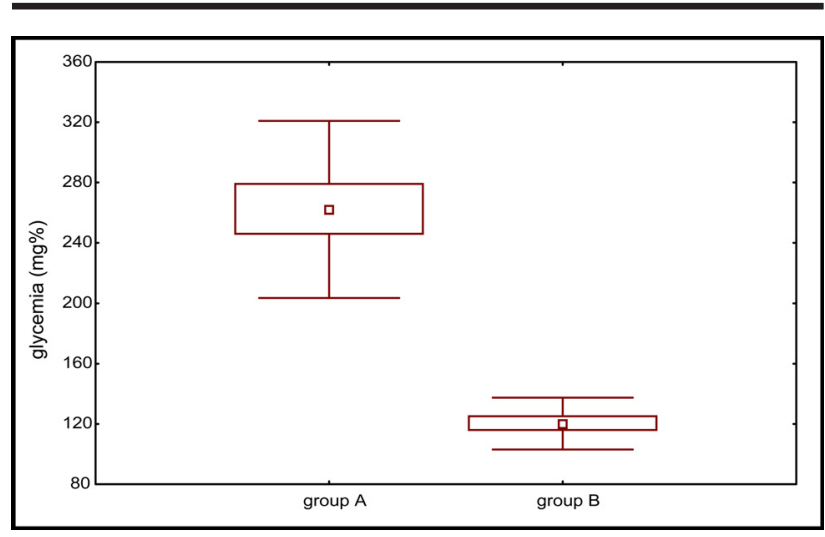

FIGURE 1 - Graphic presentation of the determination of glycemia $(\mathrm{mg} \%)$ in the animals of group A $(90$ minutes of ischemia and 15 minutes of reperfusion) and group $\mathrm{B}$ (sham operation). The comparison showed a significant difference $(p<0.05)$.

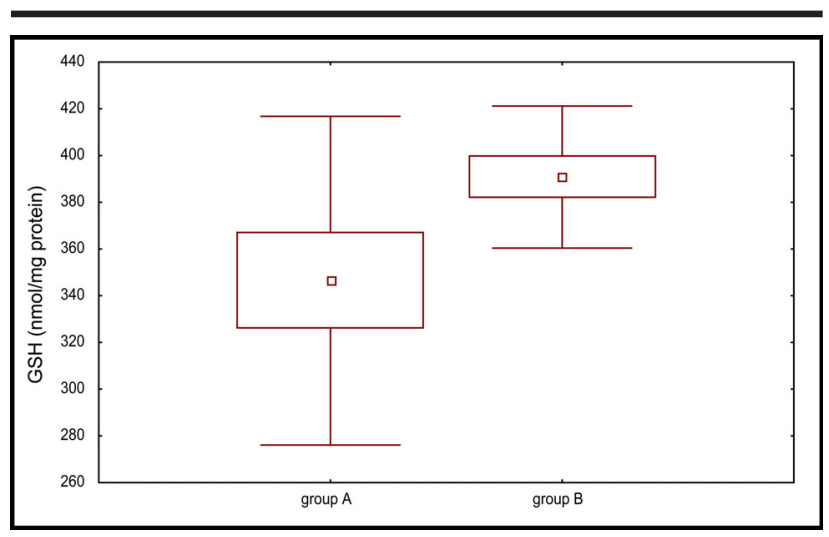

FIGURE 2 - Graphic presentation of the determination of hepatic mitochondrial glutathione (GSH in $\mathrm{nmol} / \mathrm{mg}$ protein) in the animals of group A (90 minutes of ischemia and 15 minutes of reperfusion) and group B (sham operation). The comparison showed a significant difference $(p<0.05)$.

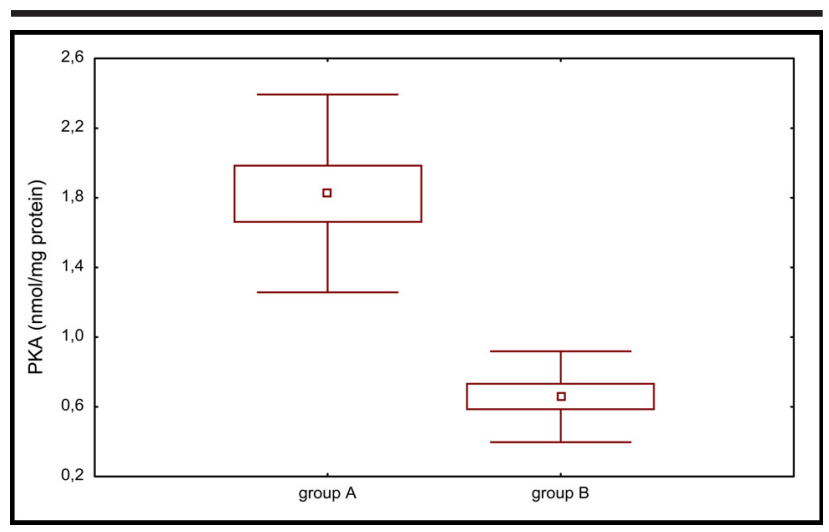

FIGURE 3 - Graphic presentation of the determination of hepatic tissue pyruvate kinase activity (PKA) in the animals of group A (90 minutes of ischemia and 15 minutes of reperfusion) and group B (sham operation). The comparison showed a significant difference $(\mathrm{p}<0.05)$. 


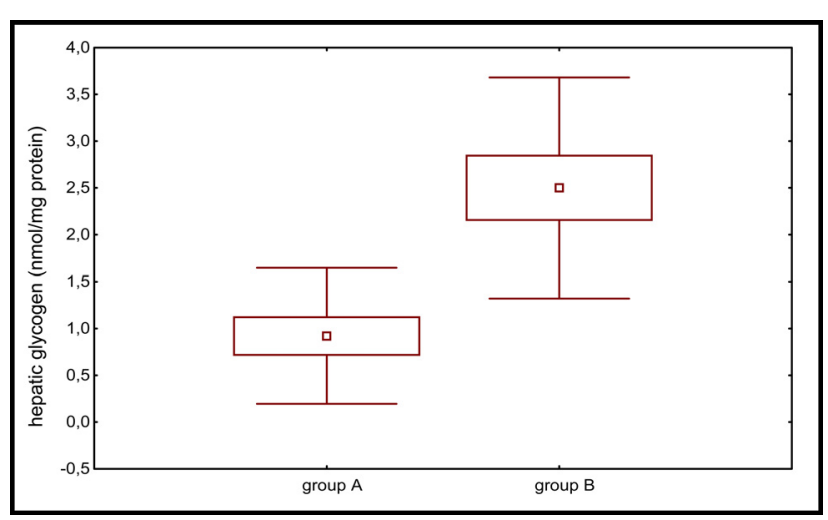

FIGURE 4 - Graphic presentation of hepatic glycogen tissue level determined in animals of group A (90 minutes of ischemia and 15 minutes of reperfusion) and group B (sham operation). The comparison showed a significant difference $(\mathrm{p}<0.05)$.

\section{Discussion}

The phenomena that occur after selective hepatic ischemia are enhanced by reperfusion, although this is theoretically the treatment for the lack of tissue oxygen ${ }^{1,2}$. The lack of blood supply to hepatic tissue causes the endothelial release of inflammatory mediators such as interleukins, cyclooxygenases, arachidonic acid metabolites, phospholipids, tumor necrosis factor, platelet activating factor, ICAM-1, and selectin. These factors alter the physiology of the microcirculation, leading to a fall in arterial pressure mainly observed after reperfusion ${ }^{11,12}$. In the present study there was a statistically significant fall in mean arterial pressure in group A (ischemic) compared to group B (sham operation). These results were expected but this determination was performed so that we could establish and verify the differences detected when analyzing the biochemistry of hepatic tissue. The activation of Kupffer cells and neutrophils caused by ischemia and reperfusion themselves may be mediated by the platelet activating factor, favoring the release of oxygen-derived free radicals and increased calcium influx especially after reperfusion, and reduction of the antioxidant agents superoxide dismutase, catalase and $\mathrm{GSH}^{6,7,8,11,12}$, leading to a reduction in NADPH and limiting the peroxide reduction by the antioxidant GSH system and increasing MDA production. Phospholipase activation may cause severe damage to the membrane lipids, changes in mitochondrial permeability and in DNA, proteins, lipids and other macromolecules and oxidative stress progressed during ischemia and triggered the oxidative injury after reperfusion $6,7,8,10,12,13$. Alanine and aspartate aminotransferases (ALT and AST), when present at high concentrations, indicate hepatocellular injury and changes in cytoplasmic membrane permeability. The ischemic group presented mean ALT levels of 1013 IU/1 after 15 minutes of reperfusion, showing that, indeed, there was acute hepatocyte injury caused by ischemia. ${ }^{13}$ This hepatic injury was also observed in terms of glycemia which presented mean levels of $262 \%$, indicating that there was glycogen mobilization, with reduced mean glycogen levels in the ischemic group, and increased basal pyruvate kinase activity. This activity was increased due to the ichemia/ reperfusion process and occurred through the glycolytic pathway. Inomoto et $\mathrm{al}^{5}$ observed that the glycolytic process is increased in both cold and warm ischemia, with a balance between glycolysis and gluconeogenesis and a reduction in phosphofructokinase only in warm ischemia. This study of the glycolytic pathway may be important to determine the most important time of injury during preservation and reperfusion. Saiki et al. suggested that phosphoenolpyruvate recovers hepatic energy from liver cell damage by prompt ATP production through the degradation into pyruvate in the liver by pyruvate kinase $\mathrm{e}^{14}$. Probably be the pyruvate kinase decrease founded in our ischemic group. Lipoperoxidation of biological membranes is a destructive process started by oxygen-derived free radicals ${ }^{5,6,7}$ causing edema and increased calcium influx with consequent mitochondrial dysfunction due to the fact that, once the ischemia/reperfusion condition is initiated, $\mathrm{H}_{2} \mathrm{O}_{2}$ and $\mathrm{OH}$ free radicals can open channels in the mitochondrial membrane by attacking the sulfhydryl groups of certain proteins exposed by $\mathrm{Ca}^{++}$binding; the increase of this ion may activate mitochondrial phospholipase $\mathrm{A}_{2}$ inducing increased $\mathrm{OH}^{\circ}$ formation. The lipoperoxides formed can be reduced by GSH and allopurinol, vitamin $\mathrm{E}$ and alphatocopherol ${ }^{6}$. Reduced GSH is a cellular antioxidant metabolized in the cell by glutathione peroxidase which catalyzes the conversion of oxygen peroxide to oxygen and water. This system of reduction by GSH is one of the processes used by the mitochondria to remain stable. During ischemic and reperfusion processes there is a loss of the mitochondiral antioxidant ability and the cells become more sensitive to the effects of excessive production of oxygenderived free radicals, and these changes are detected by the appearance of lipoperoxidation products such as MDA and the decrease in hepatic mitochondrial GSH content $6,7,8,9,11,12,13,14$. The occurrence of lipid peroxidation is measured by the increase in hepatic mitochondrial MDA and by the decrease in hepatic mitochondrial GSH that occurs after liver reperfusion ${ }^{14}$. In the present study the ischemic group (A) presented higher mean MDA levels than group B and lower mean GSH levels than group B. These results demonstrate that lipid peroxidation occurred during the process of hepatic tissue reperfusion. Changes in mean arterial pressure, acute hepatocyte injury, lipid peroxidation, and increased basal pyruvate kinase activity occurred after selective hepatic ischemia and 15 minutes reperfusion and that this activation mainly occurred through the glycolytic pathway.

\section{References}

1. Bulkley GB. Reactive oxygen metabolites and reperfusion injury: aberrant triggering of reticuloendothelial function. Lancet. 1994; 344: 934-36.

2. Grace PA. Ischemia-reperfusion injury. Br J Surg. 1994; 81:637-47.

3. Atalla SI, Toledo-Pereyra LH, Mackenzie GH, Cederna JP. Influence of oxygen-derived free radical scavengers on ischemic liver. Transplantation. 1985; 40:584-89. 
4. Ward P. Mechanisms of endothelial cell injury. J Lab Clin Med. 1991; 118:421-z6.

5. Inomoto T, Tanaka A, Awane M, Kanai M, Shinoara H, Hatano S, Sato S, Gomi T, Masuda K, Someya Y, Honda $\mathrm{K}$, Seino Y, Yamaoka Y. Changes in glucose transporter 2 and carbohydrate-metabolizing enzymes in the liver during cold preservation and warm ischemia. Transplantation. 1996; 61:869-74.

6. Fukai M, Hayashi T, Yokota R, Shimamura T, Suzuki T, Taniguchi M, Matsushita H, Todo S. Lipid peroxidation during ischemia depends on ischemia time I warmischemia and reperfusion of rat liver. Free Radic Biol Med. 2005; 38:1372-81.

7. Domenecali M, Vendemiae G, Serviddio G, Grattagliano I, Pertosa AM, Nardo B, Príncipe A, Viola A, Trevisani F, Altomare E, Bernardi M, Caraceni P.Oxidative injury in rat fatty liver exposed to ischemia-reperfusion is modulated by nutritional status. Dig Liver Dis. 2005; 37: 689-97.

8. Armeni T, Ghiselli R, Balercia G, Goffi L, Jassem W, Saba V, Principato G. Glutathione and ultrastructural changes in inflow occlusion of rat liver. J Surg Res. 2000; 88:207-14.

9. Castro e Silva O, Mies S, Beer AJr, Rocha JPS, Rizzo CC,
Zucoloto S, Ceneviva R, Raia S. Metabolic changes induced by reperfusion after warm liver ischemia. Acta Cir Bras. 1996; 11: 24-6.

10. Roselino JES, Castro e Silva O, Ceneviva R. Lack of control of liver gluconeogenesis in cholestatic rats with reduced portal blood flow. Hepatology. 1992; 15 1055-60.

11. Aggarwal S, Kang Y, Freeman J, Dewolf AM, Begliomini B. Is there a post-reperfusion syndrome? Transplant Proc. 1989; 21:3497-99.

12. Boin IFSF, Leonardi LS, Castro e Silva O Jr. Secondary alterations to ischemia/reperfusion injuries after partial hepatic ischemia in Wistar rats using WEB 2086. In: Cavallari A, Mazziotti A and Principe A, eds. $2^{\text {nd }}$ World Congress International Hepato Pancreato Biliary Association, Bologna: Monduzzi, International Proceedings Division, I. Liver 1996:149-153.

13. Ontel S, Makowka L, Trager J, Mazzaferro V, Ove P, Starzl TE. Pharmacologic modulation of experimental postischemic hepatic function. Ann Surg. 1989; 209:200-12.

14. Saiki S, Yamaguchi K, Chijiiwa K, Hamasaki N, Tanaka M. Phosphoenolpyruvate prevents the decline in hepatic ATP and energy charge after ischemia and reperfusion injury in rats. J Surg Res. 1997; 73: 59-65.

\section{Correspondence:}

Ilka de Fatima Santana Ferreira Boin

Rua Aldo de Oliveira Barbosa, 184

13086-030 Campinas - São Paulo BraziL

ilkaboin@yahoo.com
Conflict of interest: none

Financial source: $\mathrm{CNPq}$

\section{How to cite this article:}

Boin IFSF, Castro e Silva O, Souza MEJ, Santos AC, Leonardi LS. Pyruvate kinase activation and lipoperoxidation after selective hepatic ischemia in Wistar rats. Acta Cir Bras. [serial on the Internet] 2006;21 Suppl 1. Available from URL: http:/ /www.scielo.br/acb 